\title{
Study of the Contact Thermal Compression Behavior of Copper using Scanning Contact Potentiometry Method and Finite Element Analysis
}

\section{Ayman ABU GHAZAL ${ }^{1, *}$, Sara ALKHDOUR ${ }^{2}$, Yousef HUSEIN ${ }^{3}$, Vitaly SURIN ${ }^{4}$, Ghadeer AL-MALKAWI ${ }^{2}$, Raed BULBUL ${ }^{5}$ and Khaled SHATNAWI ${ }^{6}$}

${ }^{1}$ Material Testing Laboratory, Research Laboratories and Information Directorate, Nuclear Sciences and Applications Sector, Jordan Atomic Energy Commission, Amman 11934, Jordan

${ }^{2}$ Nuclear Engineering Department, Jordan University of Science and Technology, Irbid 22110, Jordan

${ }^{3}$ Nuclear Safety and Licensing Directorate, Jordan Research and Training Reactor, Jordan Atomic Energy Commission, Irbid 22110, Jordan

${ }^{4}$ Electrophysical Diagnostics and Non-Destructive Testing Laboratory, Nuclear Physics and Technology Institute, National Research Nuclear University MEPhI, Moscow 115531, Russia

${ }^{5}$ Research and Development Department, Elite-Glass Industrial Company, King Abdullah II Design and Development Bureau, Amman 2113, Jordan

${ }^{6}$ Mechanical Engineering Department, Jordan University of Science and Technology, Irbid 22110, Jordan

('Corresponding author’s e-mail: gazal.ayman@yandex.ru)

Received: 25 March 2021, Revised: 22 April 2021, Accepted: 1 May 2021

\begin{abstract}
The issue of tracking residual stresses initiation in welding copper under various affected conditions is essential in increasing safety through improving the welding quality in particular, in the nuclear industry. This study investigated the behavior of welded copper numerically and experimentally under contact-heating compression test with constant clamping force. The scanning contact potentiometry (SCP) method was used to track the initiation and development of residual stresses within the weld zone. Furthermore, the finite element analysis (FEA) method was used to simulate and study the effect of thermal variations, with a constant compressive force, on mechanical factors that contribute to residual stresses formation within the weld zone. Additionally, scanning electron microscope (SEM) and energydispersive X-ray spectroscopy (EDS) were used to get further information about the topography and composition of the specimen's surface. SCP results show that residual stress initiated from within the volume after $200{ }^{\circ} \mathrm{C}$, and with further oxidation, its formation began on the surface after $250{ }^{\circ} \mathrm{C}$. Using the relationship between maximum values of linearized von Mises stresses and maximum values of ADS at high SLS $=4.523$, it was found that residual stresses generation began after $150{ }^{\circ} \mathrm{C}$ within the weld zone, and thermal stresses linearly increase with temperature due to further thermal expansion, which is associated with variation in linearized von Mises stresses and ADS maximum values. Comparison between potentiograms after $300{ }^{\circ} \mathrm{C}$ and FEA results have shown that the distribution of von Mises stress, normal stress, and total deformation are matching those in the distribution of ADS and are localized within the weld zone.
\end{abstract}

Keywords: Compression test, Finite element analysis, Copper, Residual stresses, Scanning contact Potentiometry method 


\section{Introduction}

Non-destructive testing (NDT) is defined by the American Society for Nondestructive Testing (ASNT) as: 'The determination of the physical condition of an object without affecting that object's ability to fulfill its intended function' [1]. Scanning contact potentiometry (SCP) is a new NDT method effectively used in assessing the integrity of structures by characterizing damage in conducting materials [2-6].

SCP deals with the physical and electrical properties of conductive materials, where it is concerned in electro-physical diagnosis and studies changes in the signal spectrum due to changes in the surface roughness. The concept of SCP is based on the classical theory of the work function of metals and the modern theory of contact interaction of metal surfaces [7-10], where interaction takes place between 2 metal surfaces in contact, forming effective bridges for conduction electrons. Forces arise between the atoms of these surfaces and lead to changes in their electron shells. The magnitude of the interatomic forces depends on the gap between the metal surfaces in contact [11-13].

During the contact interaction between metal surfaces, transition electrons get transferred from the metal having a smaller work function, across the area of contact, causing an electrical potential difference between the micro rigid bodies in contact under thermodynamic equilibrium conditions [14]. The transducer used in SCP testing is capable of converting physical signals detected into a proportional electrical quantity (micro-voltage). The interaction that takes place between the transducer and the material under test can be described using statistical laws.

As external loads increase, an increase in the real contact area occurs mainly due to the increase in the number of contact points with a slight increase in their size [15]. Ordinarily, the actual contact area is 10 - 4 to 10 - 1 of the nominal contact areas and does not exceed $40 \%$ even at high loads. For a pair of metals of different hardness, the actual contact area is determined by the softer metal properties and the surface geometry of the (harder or softer) solid [16-19]. The contact between 2 metal surfaces leads to the equalization of the upper energy levels of electrons and the formation of a system in equilibrium. Moreover, the contact surface is considered to be practically ideal for the transfer of electrons from metal with a lower work function to a metal with a larger work function. This results in the creation of 2 potentials: Internal and external contact potentials causing a potential difference [20].

This in turn means that after the deformation by thermal compression, a change in the work function lead to changes in the electrical potential difference distribution which is caused by several factors including the production (generation) of residual stresses originating from non-homogeneous regions within the material [21]. Given that there is an inequality between the real contact surface area and the nominal contact area, the modern theory of contact mechanics of solids is valid.

A lot of work related to the mechanics of contact in solids is based upon the approximation of a "rough" surface using a random distribution of irregularities in the form of spherical or elliptical protrusions, which means that Hertz contact theory is valid. For some cases, elastic contact interaction of irregularities in the contact zone can be neglected, if the average distance between adjacent regions of contact for the surfaces is sufficiently large [22]. Application of external loads on material specimens causes the formation of surface deformation waves or dynamic surface roughness which leads to a change in the surface energy.

Following the changes occurring on the surface, we observe a change in the electric potential at various points of the material specimen. The "instantaneous" change in the Fermi energy during the testing process is associated with the heterogeneity of the resulting surface deformation. During the measurements using the SCP method, the work function of the transducer remains unchanged, since the specimen's deformation energy is not comparable with the deformation of local protrusions (crushing) on the contact surface of 2 metals.

A stationary transducer is usually fixed at a considerable distance from the tested gauge area of the specimen surface, while the measuring system registers the electric potential difference between the 2 measuring contacts. The work function of metals is affected by deformation, the greater the degree of deformation, the larger the change in the work function relative to its initial value $[23,24]$. The elementary act of plastic deformation is associated with the exit to the free surface of the dislocated monoatomic step 
http://wjst.wu.ac.th

[25]. During the process of intense plastic deformation, dislocations gain momentum towards the surface [26], interacts through the contact surface with the transducer material, and lead to a characterization of the electrical contact exerted by dislocation bands or Chernov-Luders bands formed during the process.

Residual stresses can be defined as a stress field that exists in the absence of any external loads on the material and is the result of mechanical processes which have caused deformation [27]. The origin of residual stresses may be due to thermal, mechanical, and chemical causes. When a metal is heated and then suddenly cooled, thermal stresses originate due to differential thermal expansion causing nonhomogeneous plastic deformation within the volume. In the absence of transformation for thermal residual stresses, then plastic deformation is crucial. If the deformation taking place during the cooling period remains within the elastic range, no residual stress remains after thermal equilibrium is reached [28].

During the welding process, residual stresses arise from thermal strains during heating and cooling cycles, in both the weld metal and the adjacent heat-affected zone (HAZ) [29]. Changes in the number and area of contact spots cause an even greater influence on the structural inhomogeneities formed within the bulk of the specimen and emit waves of mechanical stress creating reflexes. Reflex is an image of the surface potential distribution on potentiograms.

The process of SCP testing includes surface electrical reflexes being investigated under the impact of external and internal factors. The laws of solid-state deformation are used to explain the images obtained by the SCP method on potentiograms at high levels of Structural levels of signal (SLS). According to the concept of contact potentiometry, at higher structural levels, reflexes from microscopic inhomogeneities are formed on potentiograms.

Finite element analysis (FEA) can be defined as a computer numerical analysis program used to study structural stress and to conduct thermal analysis [30]. To perform FEA, the finite element method (FEM) is the numerical technique used and still by far is the most commonly used numerical tool to obtain the stress concentration factors for different types of welded joints [31]. FEA can be considered an acceptable analysis system, where the results it generates for stresses, strains, etc. are valid as 'real life' predictions. However, as with most systems, the results produced are only as good as the model developed [32].

Copper alloys have good corrosion resistance, together with a very high heat transfer coefficient and it is one of the main metallic materials used in condenser tubes and balance of plant heat exchangers of pressurized water reactors and boiling water reactors [33]. Copper is an important structural material for the nuclear industry, properties of copper making it a candidate for canisters used for high-level waste (HLW) disposal $[34,35]$. NDT includes X-ray, neutronography, ultrasound, and synchrotron methods which are usually used in the detection of residual stresses relying on measurements of stress-related parameters. Each method has its limitations. X-ray diffraction method is a lab-based method that can be used for small components and is limited for the measurement of residual stresses on the material's surface. Furthermore, ultrasonic method has limited resolution bulk measurements within the entire volume. Using a synchrotron is the fastest method for both macro and micro residual stresses; however, it needs very special equipment. Neutron diffraction has an ideal resolution but needs specialists and highcost facilities [36].

The main goal of this qualitative research is to bring out a comprehensive understanding of the powerful capabilities of the SCP method as a non-destructive technique of testing material. This investigation is assumed to be important as there exists scarce literature on the subject, in particular, of tracking residual stresses initiation, development, and distribution at an early stage within welded copper, under cyclic gradient thermal contact heating (at low temperature) tests, provided a constant compressive force is applied. Furthermore, a comparison between results obtained by the SCP method and FEA was conducted where satisfactory harmony was found. 


\section{Materials and methods}

A flat pure copper specimen having gauge dimensions of $86.58 \times 12.70 \times 2.95 \mathrm{~mm}^{3}$ was cut from the center and welded using silver alloy filler. This specimen was subjected to cyclical thermal compression under a constant load of $\sim 10,000 \mathrm{lbs}$ and gradient contact thermal temperatures of range $\left(50-300{ }^{\circ} \mathrm{C}\right)$ with a step size of $50{ }^{\circ} \mathrm{C}$. Thermal compression test was performed using Carver's automatic hydraulic laboratory press located at the Material Testing Laboratory (MTL) in Jordan Atomic Energy Commission (JAEC). For each thermal compression test, the specimen was placed between the heated plates of the presses device, the plates are at the required temperature and the compressive load was applied from the bottom, where the upper plate is fixed and the lower one is movable (Figure 1(b)). Cyclic thermal compression was performed 6 times at 6 different temperatures, with a duration of 23 min for each test. After each thermal compression test was performed, the specimen was left to cool naturally under ambient conditions. After reaching the ambient temperature following each thermal compression test, the specimen's gauge area was tested using the SCP Method in 10 horizontal measuring tracks (Figure 2), where the distance between adjacent tracks was less than $1 \mathrm{~mm}$. SCP method have been used to track the generation and development residual stresses (RS) in welding zone, through their influence on the electrical potential difference on the specimen surface. To facilitate the application of the SCP test, a semi-automated scanner device was designed using T-Flex CAD software and manufactured locally. The Material of Needle type transducers $(\varnothing 2.3 \mathrm{~mm})$ is high carbon steel and is nickel corrosion resistant with a sensitivity of $0.01 \mu \mathrm{V}$. The scanning speed of the movable transducer used during tests was $0.3 \mathrm{~mm} / \mathrm{s}$, where the fixed transducer was connected to the shoulder of the specimen outside the gauge area. Measured data were automatically collected and recorded, where the electrical signals were digitized at a sampling rate of $1 \mathrm{~Hz}$ and saved using a special measuring information system including a programmable amplitude discriminator of measuring signals with an adjustable amplitude discrimination scale in the range of $40 \mathrm{~dB}$. The purpose of the discriminator is to cut off the signal amplitude values located above the set threshold value, which allows the study of the electrical potential distribution at different Structural levels of Signal (SLS). The hardware and software complex of the diagnostic system is controlled using the windows operating system. A schematic diagram of the experimental setup used during the SCP method application is shown in Figure 1(a).

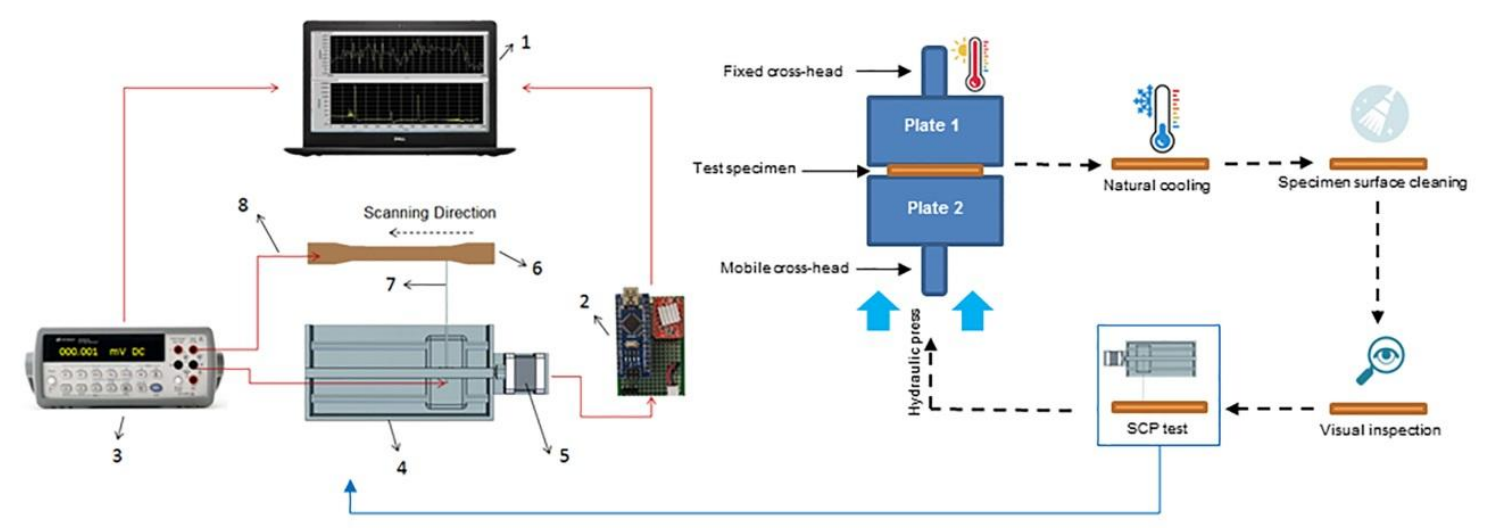

(a)

(b)

Figure 1 (a) Scheme of the SCP experiment set up: (1): Measuring information system. (2): Arduino nano V3.0 with ATmega328P Micro-Controller and stepper motor driver A4988 (3): high-sensitivity Digital Multimeter Agilent 34401A 61/2. (4): Stainless steel body of the semi-automated scanner device. (5): Stepper motor. (6): Test specimen. (7): Movable transducer (needle type). (8): Fixed transducer. (b): Scheme of the cyclical gradient thermal contact heating test process.

4 of $14 \quad$ Walailak J Sci \& Tech 2021; 18(16): 22795 


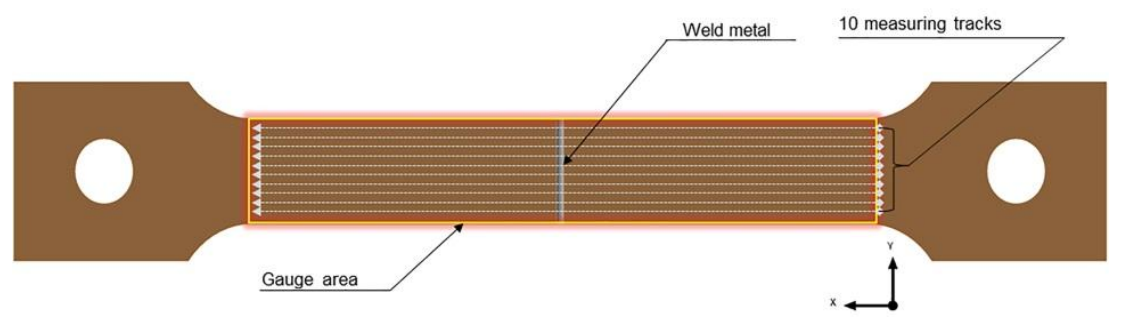

Figure 2 Copper specimen's gauge area.

SEM microscopy and energy dispersive X-Ray spectroscopy (EDS) were conducted using the scanning electron microscope (SEM) FEI Quanta 600 including an EDX system for compositional analysis located at water, environment, and arid regions research center in Al al-Bayt University, Mafraq city, Jordan. SEM and EDS analysis performed on the surface of the welded copper specimen took place after finishing the last cyclic thermal compression (after $300{ }^{\circ} \mathrm{C}$ ) and SCP tests. The specimen's gauge area was cut into 3 parts to place it safely inside the SEM test vacuum chamber. During SEM and EDS analysis of the surface specimen, regions of interest were selected according to visual observations noticed after performing all thermal compression tests.

FEA has been used to simulate the effect of thermal variations at constant compressive applied force on mechanical factors that contribute to residual stresses formation in the welding zone through studying the distribution of the von Mises stress, linearized equivalent stress, normal stress, and total deformation. When applying FEA, the specimen undergoing thermal compression tests that we analyzed, was meshed in finite subdomains bounded by rectilinear or curvilinear boundaries. Through this operation, the real specimen is replaced with a network of so-called finite elements. Differential equations were used to describe the specimen behavior which was verified for each element. The mathematical construction of the finite elements ensures a certain degree of approximate continuity at the crossing of boundaries between the elements. Continuity is achieved using nodes associated with the elements. The mesh of the welded copper specimen model has been generated using 1439 nods and 494 elements. The specimen was built using the Ansys Space Claim's, following the specification and dimensions given. The $1^{\text {st }}$ step in the modeling was the realization of the $2 \mathrm{D}$ sketch and imposing the geometric and dimensional constraints. After making the sketch it was turned into a solid model. The material from which the specimen model was made is known to be a copper alloy which has been chosen for this study and pure silver for welding filler, this was specified using the Ansys simulation software. Table 1 shows the properties of the copper alloy and pure silver.

Table 1 Thermo-mechanical properties of copper alloy and silver making up the welded copper specimen model.

\begin{tabular}{lcc}
\hline Property & Copper alloy & Pure silver \\
\hline Young's Modulus, $\mathrm{MPa}$ & $1.1 \times 10^{5}$ & 72907 \\
Poisson's Ratio & 0.34 & 0.37 \\
Mass density, $\mathrm{kg} / \mathrm{mm}^{-3}$ & $8.3 \times 10^{-6}$ & $1.049 \times 10^{-5}$ \\
Compressive yield strength, MPa & 280 & 45 \\
Tensile yield strength, MPa & 99.5 & 54.08 \\
Thermal expansion coefficient, $\mathrm{C}^{-1}$ & $1.8 \times 10^{-5}$ & $1.991 \times 10^{-5}$ \\
Thermal conductivity, W/mm. ${ }^{\circ} \mathrm{C}$ & 0.401 & 0.42002 \\
Specific heat, $\mathrm{mJ} / \mathrm{kg} \cdot{ }^{\circ} \mathrm{C}$ & $3.85 \times 10^{5}$ & $2.3416 \times 10^{5}$ \\
\hline
\end{tabular}


Restrictions were imposed on the upper part of the welded copper specimen model as a fixture to match the non-moving upper plate of the hydraulic press while load is being applied from the bottom (Figure 3). After selecting the material and the meshing of the model, the imposition of boundary condition as close up to the real experiment such as cyclical loading force and heating, we were able to proceed to the running of the simulation.

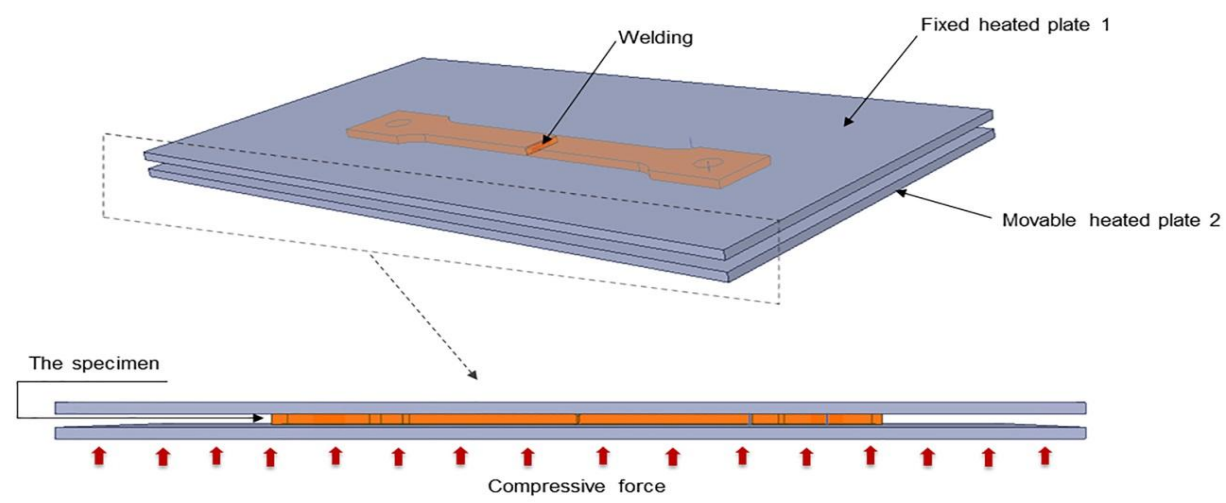

Figure 3 Conditions of the compression test simulation of the welded copper specimen with constant clamping force $\sim 10,000 \mathrm{lbs}$ and gradient contact thermal heating temperatures of range $\left(50-300{ }^{\circ} \mathrm{C}\right)$ with a step size of $50^{\circ} \mathrm{C}$.

\section{Result and discussion}

Visual inspection (VI) results show oxide formation on the surface of the copper specimen. Results are shown in Figure 4 and changes in the color of the copper specimen [37]. It can be observed the sequential color change started after a temperature of $150^{\circ} \mathrm{C}$.

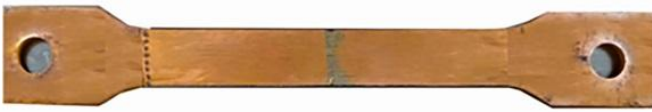

(a)

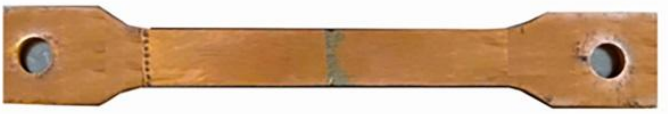

(b)

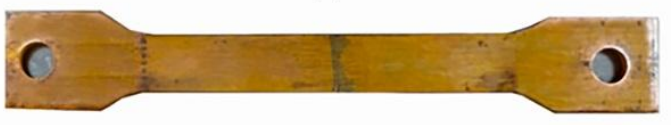

(c)

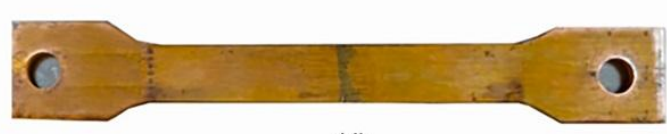

(d)

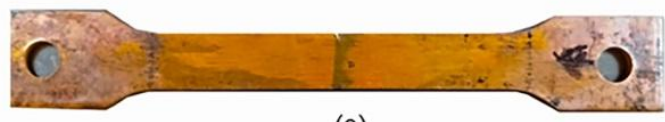

(e)

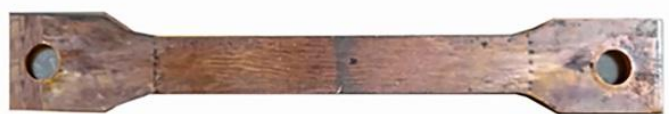

(f)

Figure 4 Images of the welded copper specimen for visual inspection. (a): After $50{ }^{\circ} \mathrm{C}$. (b): After $100{ }^{\circ} \mathrm{C}$. (c): After $150{ }^{\circ} \mathrm{C}$. (d): After $200^{\circ} \mathrm{C}$. (e): After $250^{\circ} \mathrm{C}$. (f): After $300^{\circ} \mathrm{C}$. 
The SEM images of regions corresponding to the EDS analysis on the surface of the copper specimen show compression test and impurity is affected on the surface morphology (Figure 5).

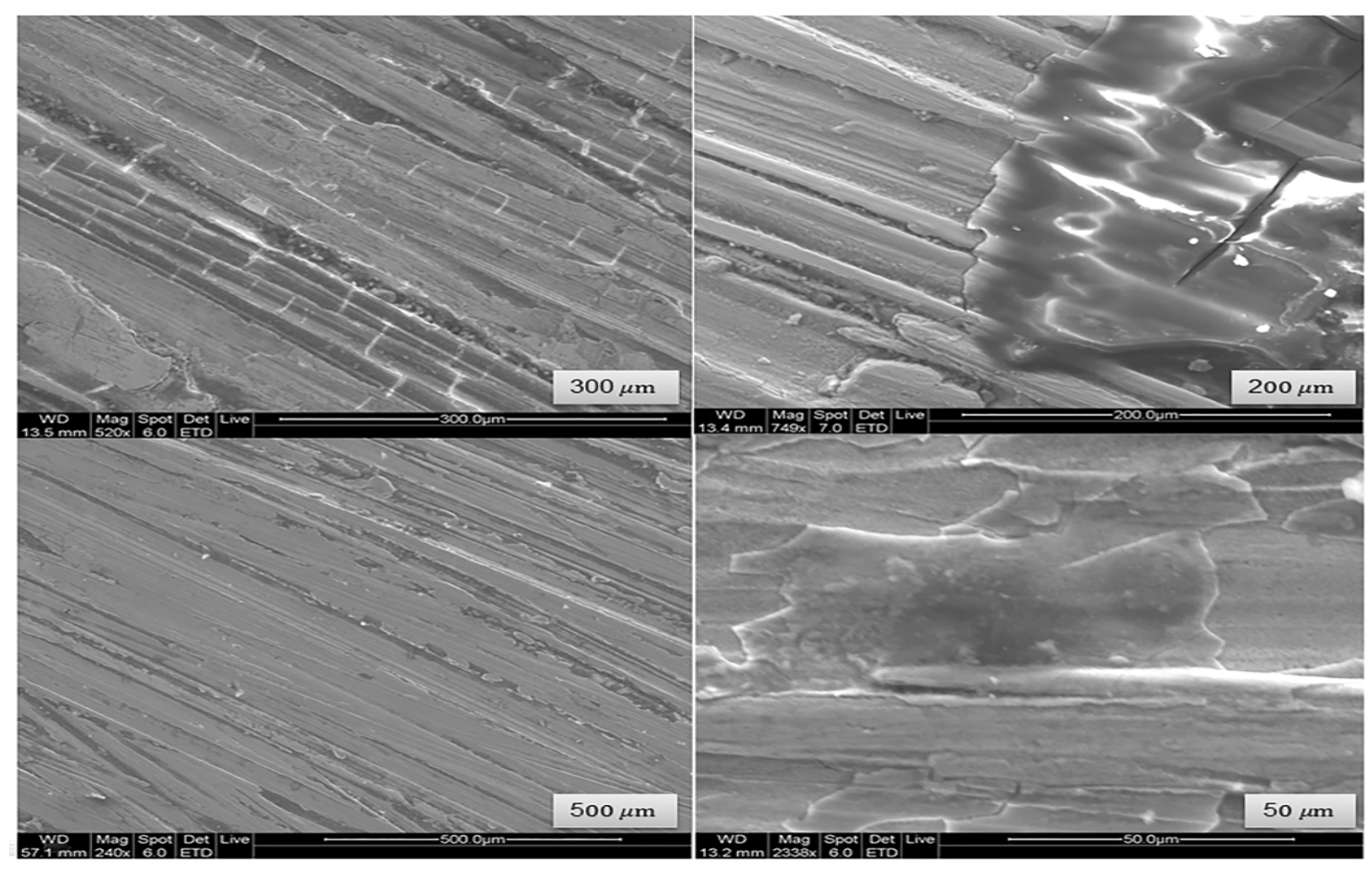

Figure 5 SEM images of regions where EDS analysis was performed on the surface of the tested copper specimen after the last thermal compression test $\left(300^{\circ} \mathrm{C}\right)$.

EDS chemical composition results confirm the existence of (in wt. \% by specimen): $\mathrm{O} / 13.85$ and $\mathrm{C} / 105.06$ in all analyzed regions. The presence of carbon is associated with oxygen as shown in table 2 due to oxidation and the presence of impurities. The oxygen content in EDS analysis results is lower than 30 at \%, which may be due to the fact that the oxidation layer is composed of $\mathrm{Cu}_{2} \mathrm{O}$ and $\mathrm{Cu}$ [38].

Table 2 EDS analysis results for regions in SEM images of copper specimen's surface.

\begin{tabular}{lccccccccc}
\hline \multirow{2}{*}{ Analyzed regions on copper's surface } & \multicolumn{9}{c}{ Weight \% by Element } \\
\cline { 2 - 9 } & $\mathbf{C}$ & $\mathbf{O}$ & $\mathbf{P}$ & $\mathbf{A g}$ & $\mathbf{A l}$ & $\mathbf{S i}$ & $\mathbf{C l}$ & $\mathbf{F e}$ & $\mathbf{C u}$ \\
\hline Small black spot & 30.01 & 2.60 & --- & -- & 0.45 & 0.96 & 0.63 & 5.17 & 60.18 \\
Clear spot & 1.81 & 0.87 & --- & --- & --- & -- & --- & -- & 97.32 \\
Black spot & 56.46 & 7.25 & --- & -- & --- & -- & --- & 4.96 & 31.33 \\
Welding region & 11.44 & 1.95 & 0.90 & 0.12 & --- & -- & --- & --- & 85.59 \\
Clear region & 5.34 & 1.18 & --- & --- & --- & --- & --- & --- & 93.47 \\
\hline
\end{tabular}

Variation in the mean Amplitude of Diagnostic Signal (ADS), representing an electrical potential difference, obtained during SCP tests performed, with temperature after thermal exposure (after natural cooling) viz. 50, 100, 150, 200, 250 and $300^{\circ} \mathrm{C}$ at various SLS is shown in Figure 6. The trend in mean ADS starts sharply changing after $250^{\circ} \mathrm{C}$ for SLS 1 and 2, but for SLS $=3$ and SLS $=4$, it is after 200 
${ }^{\circ} \mathrm{C}$. Changes in high SLS began before lower SLS, which indicates that the internal residual stresses within the volume were larger, while layers closer to the surface, where the formation of the surface oxide layer took place, caused changes in the trend at SLS $=1$ and SLS $=2$ after $250{ }^{\circ} \mathrm{C}$. This is associated with changes in the oxide color in Figure 4(e).

The mean of the diagnostic signals detected by the transducer during SCP testing were plotted against the temperature of each test (with the same compression load of 10,000 lbs. being applied) at different depths within the volume, represented by the Structural Level Signals (SLS). The higher the SLS value the deeper within the volume is the initiation of the detected diagnostic signal, indicating a deeper non-homogeneity.

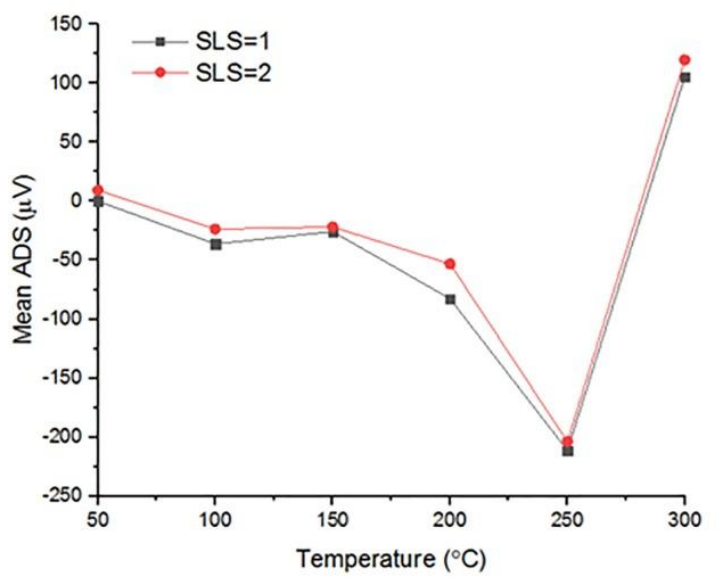

(a)

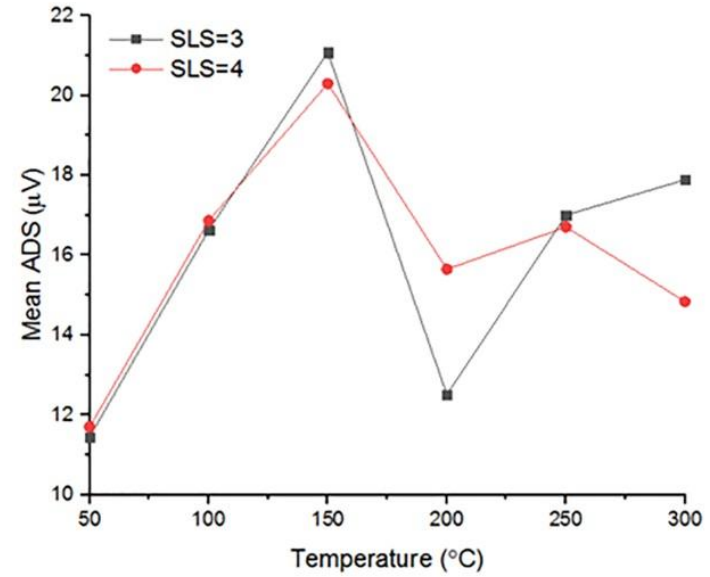

(b)

Figure 6 Variation in mean ADS, with temperature after gradient (cyclical) thermal and compression exposure for various SLS.

The FEM analysis results have shown that the mean of von Mises stresses increased with increasing test temperature after each thermal constant compression load test. Figure 7(a) shows the variation in mean ADS for all SLS with mean von Mises stresses. It can be noticed that the trend started changing after $\quad 150{ }^{\circ} \mathrm{C}$ and continued increasing exponentially. From Figures 7(a) and (b) similar trend of maximum values of linearized von Mises stresses and maximum values of ADS at high SLS $=4.523$ was found. The trend of both values started changing after $150{ }^{\circ} \mathrm{C}$. Using FEA, maximum values of linearized von Mises stresses occurred within the weld zone which reached $2115.9 \mathrm{MPa}$ after $150{ }^{\circ} \mathrm{C}$, this exactly corresponds to the potentiograms where maximum values of ADS reached $29.3 \mu \mathrm{V}$ and were localized within the weld zone at SLS $=4.523$ (Figure 9 (d)).

The mean of von Mises stress (MPa) within the sample recorded during the simulation of the thermal compression tests is plotted against each test's temperature (6 temperatures for 6 tests). In addition to that, an axis is added to indicate the Mean Amplitude diagnostic signal detected during each SCP test, to show its proportionality and variation with the mean von Mises stresses. While Figure 7(b) shows the Maximum linearized von Mises stresses recorded during the numerical simulation using the FEA method being plotted against each thermal compression test's temperature, and an axis is added to indicate maximum ADS detected during SCP scanning of each test. 


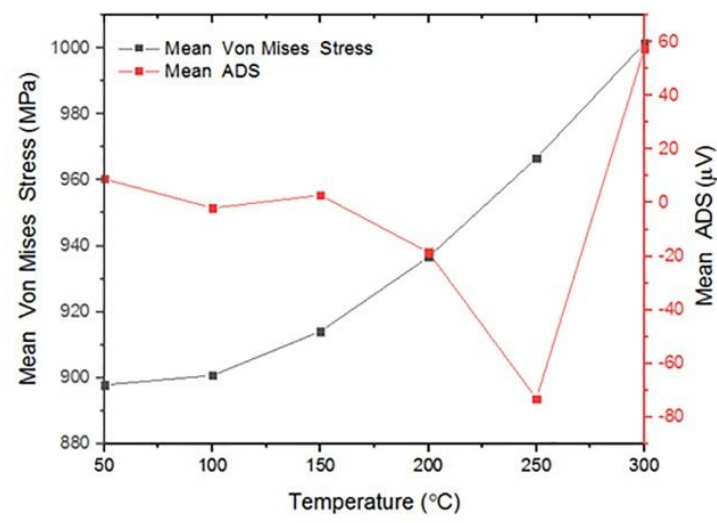

(a)

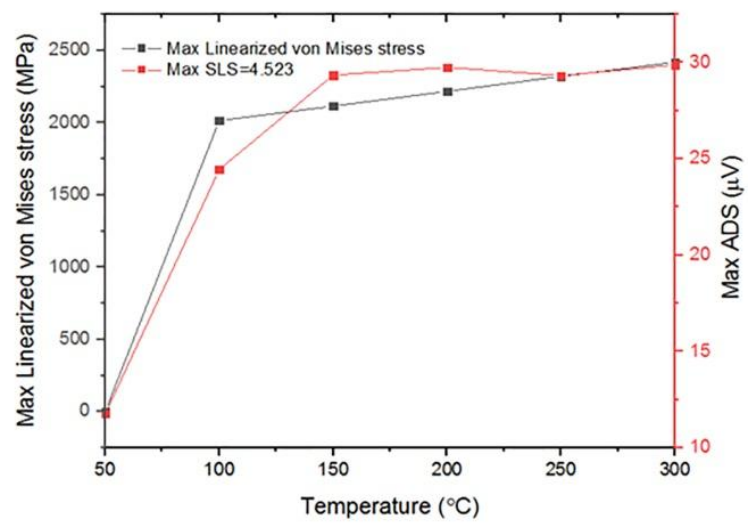

(b)

Figure 7 Variation shown from numerical FEA (simulation) and experimental ADS results with temperature after each hot-compression cyclical test.

During FEM simulation and SCP experimental results analysis, it was found that one of the main factors influencing the residual stresses initiation is the temperature at which the constant load is applied. Therefore, increasing cyclic heating temperature with constant applied load causes increasing Von Misses stresses to develop within the weld zone, which is reflected in the variation of ADS collected during SCP experimental tests. Figure 8 shows variation in Von Misses stress and ADS after performing thermalcompression cyclic tests. These results are harmonious with those in works $[39,40]$ about thermal expansion. By calculating thermal stresses $\sigma_{\text {thermal }}$ using the known following equation:

$\sigma_{\text {thermal }}=E \alpha(\Delta T)$

Where $E$ is the young's modulus for the material under test, $\alpha$ is the coefficient of thermal expansion and $\Delta T$ is the difference between final and initial temperatures, it is noticed that changes in von Mises stresses and ADS are associated with changing thermal stresses.

The effect of the variation in temperature and thermal stresses initiated within the specimen during each test is related to the maximum detected ADS during SCP, and to the maximum recorded linearized von Mises stresses during FEA numerical simulation of thermal compression tests, where results are shown in Figure 8.

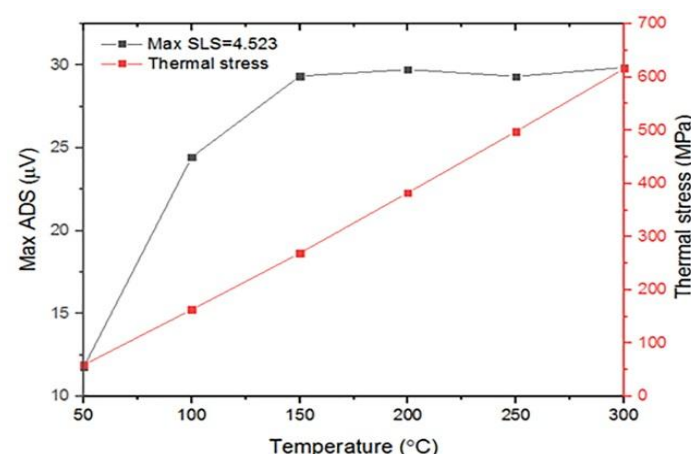

(a)

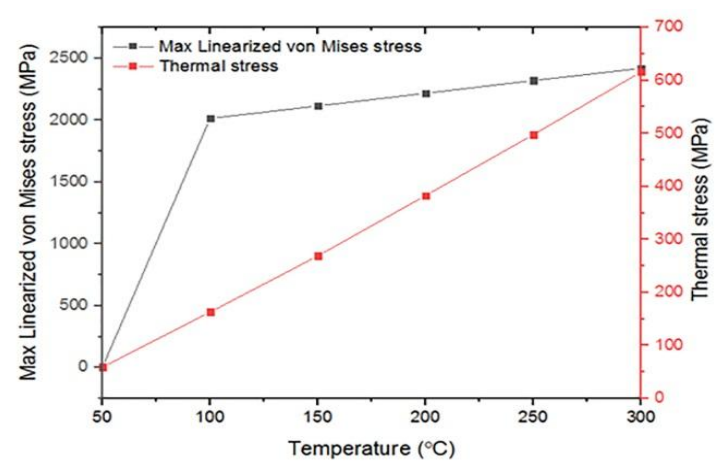

(b)

Figure 8 Variation in FEA numerical (simulation) and ADS (experimental) results with thermal stresses for temperature after each thermal-compression cyclical test. 
The presence of residual stresses is temperature-dependent and is due to the effective coefficients of thermal expansion being significantly different along with different specimen directions. Subsequently, thermal expansion between different constituent materials lead to changes in thermal residual stresses, affecting the strength and integrity of the welded copper specimen under test, [41] this is most significant at the weld zone of dissimilar metals, where high residual stresses have been induced lead to degradation in the integrity of the joint [42]. SCP results are also presented using potentiograms shown in Figure 9 Potentiograms show the distribution of the electrical potential difference across the specimen's surface gauge area, measured in 10 (Y-axis) tracks with a duration of $271 \mathrm{~s}$ scanning time (X axis), meaning a scanning length of $89 \mathrm{~mm}$ for each track.

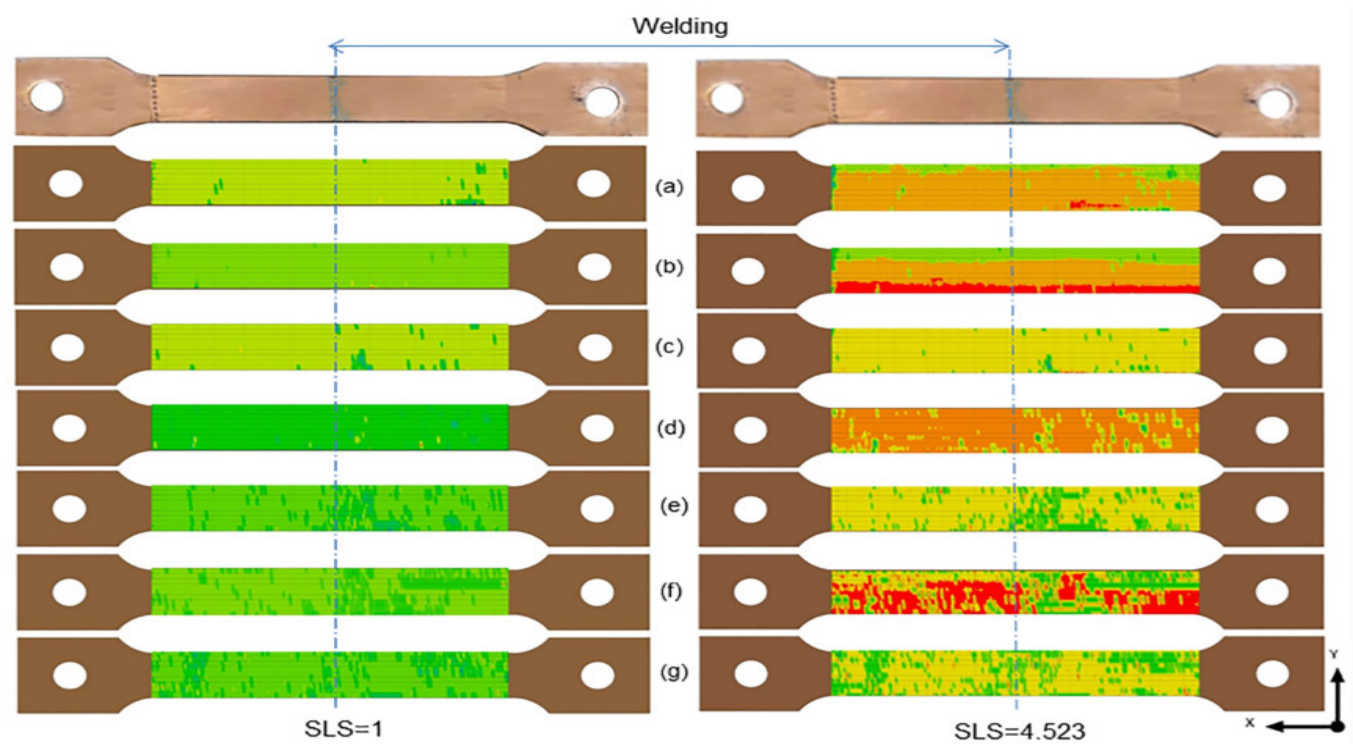

Figure 9 Potentiograms at SLS $=1$ (left) and SLS $=4.523$ (right). Upper pictures are real images of the gauge area, where the welded region is shown at the center of the specimen. (a): Before starting the thermal compression test (under the ambient condition without applying any external loads). (b): After 50 ${ }^{\circ} \mathrm{C}$ test. (c): After $100{ }^{\circ} \mathrm{C}$ test. (d): After $150{ }^{\circ} \mathrm{C}$ test. (e): After $200{ }^{\circ} \mathrm{C}$ test. (f): After $250{ }^{\circ} \mathrm{C}$ test. (g): After $300{ }^{\circ} \mathrm{C}$ test.

Potentiogram in Figure 9(d) at SLS $=4.523$ shows that the intensity of the signal is concentrated near to the HAZ. Furthermore, in Figure 9(d) at SLS = 1, it can be seen that the intensity of the signal starts to concentrate near to the HAZ. Also, in Figure 9(f) at SLS $=4.523$ it can be observed that the intensity is accumulating in the region close to the weld zone (HAZ). It can also be observed that intense concentration increases and becomes closer to the weld zone with an increase in exposure temperature, until $300{ }^{\circ} \mathrm{C}$. From the potentiograms shown, we can conclude that the signal intensity initiated from residual stresses near HAZ began after the performance of the $150{ }^{\circ} \mathrm{C}$ thermal compression test (Figure 9(d)). At high SLS $=4.523$, after $200{ }^{\circ} \mathrm{C}$, it can be noticed that residual stresses began to form on the surface which confirms that ADS intensity is high at SLS $=1$ (Figure 9(e)). After the $250{ }^{\circ} \mathrm{C}$ test (Figure 9 (f)), both SLS $=1$ and SLS $=4.523$, show an increase in residual stresses and intensity approaching the weld zone. Results match those from VI and EDS about oxidation and are related to those published [4345], which confirms that residual stresses grow in an oxidized surface layer. However, the oxide layer is very thin; its thickness ranges from 10 to $50 \mathrm{~nm}$ [38], which means that its effect is negligible in forming and changing the trend of ADS. Therefore, the residual stresses in the oxide layer or in the bulk of the specimen play a big role (domain) in forming of ADS. Variation in ADS depends on changes in the work 
http://wjst.wu.ac.th

function of the material under test [21], which indicates the formation of residual stresses. It is known for any material, after being exposed to thermal or compression loads, residual stresses are initiated with the bigger compressive residual stress occurs, the closer surface [46]. According to the SCP concept, at low structural levels SLS $=1$ and SLS $=2$, reflexes are initiated from the upper layers near to the surface of the specimen, where an increase in the residual stresses was from the oxidation of copper at low temperatures [38].

(a)

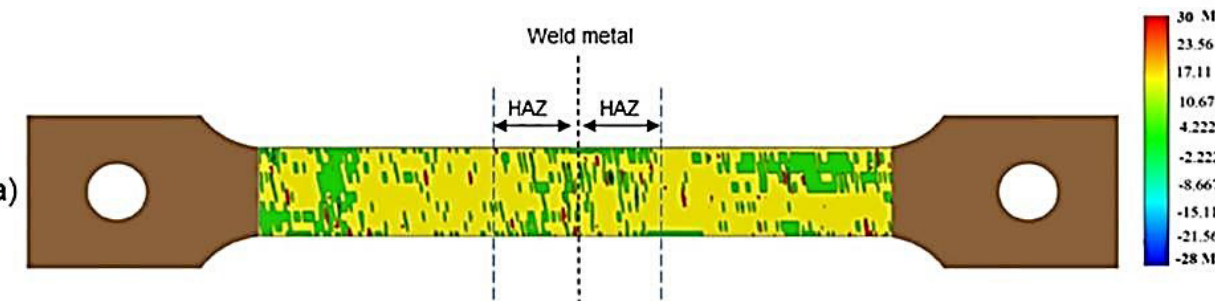

(b)

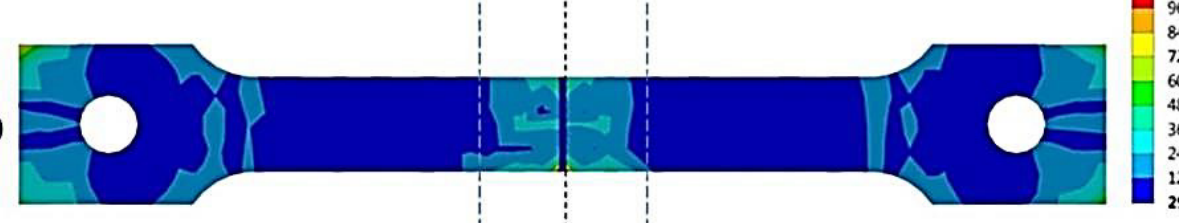
96265 72272 6027.6 6027.6 36283 24286 1228 $22.358 \mathrm{Min}$ 0.14164 Max 0.12613 0.11062

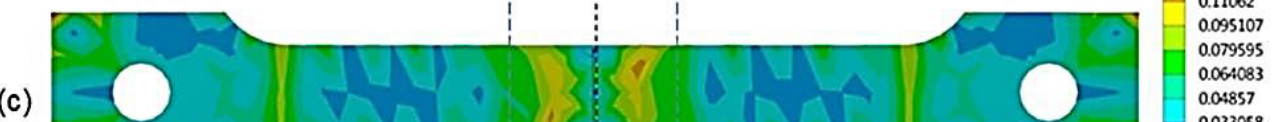

(c)

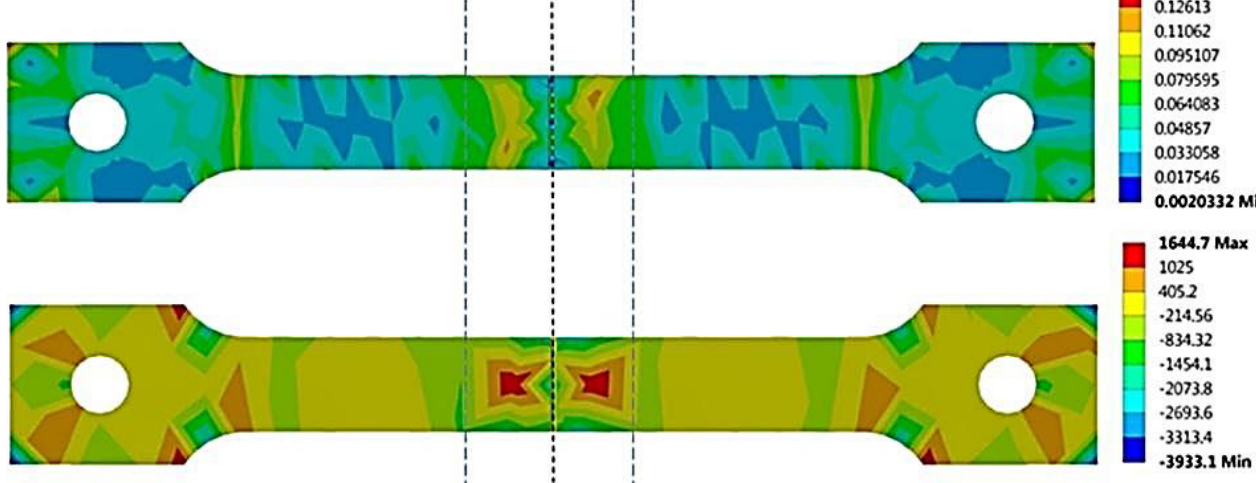

Figure 10 FEA simulation and SCP experimental summary results after $300{ }^{\circ} \mathrm{C}$ test. (a): Potentiogram at $\mathrm{SLS}=4.523$ distribution of the electrical potential difference in $\mu \mathrm{V}$. (b): Equivalent (Von Mises stress) in $\mathrm{MPa}$. (c): Total deformation in mm. (d): Normal stress (z-axis - Perpendicular to the surface) in MPa.

Fitting between simulation and experimental results can be viewed of the intensity of ADS is localized around the weld zone in the HAZ and has a maximum value of $30 \mu \mathrm{V}$. Figure 10(b) shows that the highest von Misses stress intensity is around the weld zone (in HAZ). It has been seen that von Mises stress values increase as the HAZ is approached. It was also noticed that the deformed area located around the welding shown in Figure 10(c) has reached maximum values within the HAZ. The maximum normal stress concentration is surrounding the weld zone (in HAZ) which has reached a value of $\approx$ $1,640 \mathrm{MPa}$. 


\section{Conclusions}

In this research, the effect of cyclic gradient contact heating with a constant compressive applied load on the development of residual stresses within the weld zone was investigated using the SCP method and FEA numerical simulation. VI of the copper welded specimen surface has shown the formation of the oxidized layer causing a sequential change in color that has started after a temperature of $150{ }^{\circ} \mathrm{C}$. EDS chemical composition analysis results have shown that the surface of the specimen (at all analyzed regions) contained oxygen 13.85 at $\%$ and was associated with the presence of carbon that is known to be due to oxidation and the presence of impurities. With that being said, as the oxygen content is less than $30 \%$ this may refer to the fact that the oxidized layer was composed of $\mathrm{Cu}_{2} \mathrm{O}$ and $\mathrm{Cu}$. SEM images show both thermal compression test and impurity is affected on the surface of the copper specimen's morphological texture. SCP results through the variation of mean ADS with temperature have shown the residual stresses starting to form from within the specimen's volume after $200{ }^{\circ} \mathrm{C}$, followed by further oxidation that began to form on the surface after $250{ }^{\circ} \mathrm{C}$. IN other words, the residual stress effect was from within the volume of the specimen, and with increasing temperature their effect within the oxidized surface dominated. The SCP results were demonstrated using the potentiograms and showed the localization of residual stresses starting at an early stage within the weld zone after $100{ }^{\circ} \mathrm{C}$. The relationship between maximum values of linearized von Mises stresses and maximum values of ADS at high SLS $=4.523$ has shown that the generation of residual stresses began after $150{ }^{\circ} \mathrm{C}$ within the weld zone. It was observed that thermal stresses linearly increase with the increase in temperature due to the increased thermal expansion, which was associated with variation in the linearized von Mises stresses and ADS maximum values. Comparison in potentiograms and FEA after $300{ }^{\circ} \mathrm{C}$ have shown that the distribution of von Mises stress, normal stress, and total deformation is matching with the distribution of ADS and are localized within the weld zone. Simulation has successfully shown the effect of thermal variations at constant compressive applied force on mechanical factors that have contributed to residual stresses formation within the weld zone which was done using FEA and a satisfactory linkage was drawn with SCP experimental results for their factors affecting the formation of ADS during the test, such as any deformation or additional stresses.

\section{Acknowledgement}

The authors very much appreciate the support provided by the Russian Foundation for Basic Research (RFBR) [grant number 19-08-00266/20, 25.03.2020]. The authors also acknowledge the Heads of the Jordan Atomic Energy Commission, Jordan University of Science and Technology, and the National Research Nuclear University MEPhI for their continuous support and cooperation in applied scientific research without limits or obstacles. Partial support for the work was provided by Engineer Soha Shehab from Al Arfaj Commercial \& Imports Company for her impressive figure graphic design.

\section{References}

[1] D Forsyth. 5 - Nondestructive testing of corrosion in the aerospace industry. In: S Benavides (Ed.). Corrosion Control in the Aerospace Industry. $1^{\text {st }}$ ed. Woodhead Publishing, US Coast Guard, USA, 2009, p. 111-30.

[2] V Surin. New potential for potentiometry. Nucl. Eng. Int. 2018; 63, 30-2.

[3] AA Ghazal, P Dzhumaev, A Osintsev, V Polsky and V Surin. Experimental investigation of the failure of steel AISI 316 by the methods of structural analyses. Lett. Mater. 2019; 9, 33-8.

[4] AA Ghazal, G Bokuchava, I Papushkin, V Surin and E Shef. The application of scanning contact potentiometry method and diffraction of thermal neutrons at physico-mechanical tests of materials. In: Proceedings of the XIII International Youth Scientific and Practical Conference Future of Atomic Energy, Obninsk, Russia, 2017, p. 109-26.

[5] AA Ghazal, V Surin, G Bokuchava and I Papushkin. Tracking martensitic transformation in AISI 321 stainless steel using scanning contact potentiometry and thermal neutron diffraction. In: 
http://wjst.wu.ac.th

Proceedings of the International Conference Condensed Matter Research at the IBR-2, Dubna, Russia. 2020, p. 115-6.

[6] V Surin. 2017, Method for local detection of defects and a device for implementing this method (options), Russia. Patent WO 2017/180007.

[7] HY Fan. Contacts between metals and between a metal and a semiconductor. Phys. Rev. 1942; 62, 388.

[8] JR Smith. Self-consistent many-electron theory of electron work function and surface potential characteristics for selected metals. Phys. Rev. 1969; 181, 522.

[9] ND Lang and W Kohn. Theory of metal surfaces: Work function. Phys. Rev. B 1971; 3, 1215.

[10] B Ehrhart, B Valeske and C Bockenheimer. Non-destructive evaluation (NDE) of aerospace composites: Methods for testing adhesively bonded composites. In: VM Karbhari (Ed.). Nondestructive evaluation (NDE) of polymer matrix composites. $1^{\text {st }}$ ed. Woodhead Publishing, Philadelphia, 2013, p. 220-36.

[11] J Ferrante and JR Smith. Theory of metallic adhesion. Phys. Rev. B 1979; 19, 3911.

[12] JH Rose, J Ferrante and JR Smith. Universal binding energy curves for metals and bimetallic interfaces. Phys. Rev. Lett. 1981; 47, 675.

[13] D Maugis and HM Pollock. Surface forces, deformation and adherence at metal microcontacts. Acta Metall. 1984; 32, 1323-34.

[14] JC Poole. Encyclopedic dictionary of condensed matter physics. Vol I. Academic Press, Massachusetts, 2004, p. 1672.

[15] S Andrea and S Martin. Experimental friction behaviour of elastomers on glass. In: T Martin and C Fang (Eds.). Automotive buzz, squeak and rattle. $1^{\text {st }}$ ed. Butterworth-Heinemann, Oxford, 2012, p. 223-49.

[16] D Tabor. Modern problems in friction and lubrication. Nature 1958; 182, 980-1.

[17] Y Drozdov, V Archegov and V Smirnov. Antiseize resistance of rubbing bodies (in Russian). Nauka, Moscow, 1981, p. 129-38.

[18] V Surin, N Evstyukhin and S Oborin. Spectral analysis of the contact potential difference during long-term fatigue tests of the alloy D16T (in Russian). Nauchnaya sessiya MIFI-Annotatsiya dokladov 2009; 1, 255.

[19] VM Baranov, EM Kudryavtsev, GA Sarychev and VM Schavelin. Acoustic emission during friction (in Russian). Energoatomizdat 1998; 1, 256.

[20] LB Loeb. The contact potential difference or Volta potential. In: Static Electrification. Springer, Berlin, Heidelberg, 1958, p. 32-58.

[21] VV Levitin, S Loskutov and V Pogosov. Influence of deformation and residual stresses in metals on the electron work function. Fiz. Met. Metall. 1990; 9, 73.

[22] QJ Wang and D Zhu. Hertz theory: Contact of ellipsoidal surfaces. In: QJ Wang and YW Chung. (eds.). Encyclopedia of Tribology. Springer, Boston, 2013.

[23] AV Babich and VV Pogosov. Effect of dielectric coating on the electron work function and the surface stress of a metal. Surf. Sci. 2009; 603, 2393-7.

[24] R Wang, J Li, Y Su, L Qiao and A Volinsky. Changes of work function in different deformation stage for 2205 duplex stainless steel by SKPFM. Proc. Mater. Sci. 2014; 3, 1736-41.

[25] S Loskutov. Patterns of energy relief formation of a metal surface (in Russian). Bull. Zaporizhia State Univ. 1999; 4, 1.

[26] M Shtremel. Strength of alloys (in Russia). Part 2. Deformation. M.: MISIS. 1997.

[27] MM Shokrieh and ARG Mohammadi. The importance of measuring residual stresses in composite materials. In: MM Shokrieh (Ed.). Residual stresses in composite materials. $2^{\text {nd }}$ ed. Woodhead Publishing, Philadelphia, 2014, p. 375-84.

[28] BN Das and MS Mitra. Residual stress and its effect on service. In: Proceedings of the Symposium on Industrial Failure of Engineering Metals \& Alloys, Jamshedpur, India. 1953, p. 302-12.

[29] J Hornsey. Residual stresses: Their causes, and the effective means of treatment to reduce the residual stresses and to improve the fatigue life in engineering components. Vibratory Stress Relieving 2006; 1, 18. 
http://wjst.wu.ac.th

[30] DV Rosato and DV Rosato. Computer-aided design. In: DV Rosato (Ed.). Plastics engineered product design. $1^{\text {st }}$ ed. Elsevier Science, Amsterdam, 2003. p. 344-80.

[31] ST Lie, CK Lee and SM Wong. Modeling and mesh generation of weld profile in tubular Y-joint. $J$. Construct. Steel Res.2001; 57, 547-67.

[32] O Peter. Evaluation (validation and verification). In: P Ogrodnik (Ed.). Medical device design. $2^{\text {nd }}$ ed. Academic Press, China, 2020, p. 201-53.

[33] F Cattant, D Crusset and D Féron. Corrosion issues in nuclear industry today. Mater. Today 2008; 11, 32-7.

[34] RH Bryan and IT Dudley. Estimated quantities of materials contained in a 1000-MW(e) PWR power plant. Oak Ridge National Laboratory, Tennessee, 1974, p. 1-51.

[35] L Werme, P Sellin and N Kjellbert. Copper canisters for nuclear high level waste disposal corrosion aspects. Swedish Nuclear Fuel and Waste Management Co, Stockholm, 1992, p. 1-30.

[36] NS Rossini, M Dassisti, KY Benyounis and AG Olabi. Methods of measuring residual stresses in components. Mater. Des. 2012; 35, 572-88.

[37] M Walkowicz, P Osuch, B Smyrak, T Knych, E Rudnik, Ł Cieniek, A Różańska, A Chmielarczyk, D Romaniszyn and M Bulanda. Impact of oxidation of copper and its alloys in laboratory-simulated conditions on their antimicrobial efficiency. Corrosion Sci. 2018; 140, 321-32.

[38] SK Lee, HC Hsu and WH Tuan. Oxidation behavior of copper at a temperature below $300{ }^{\circ} \mathrm{C}$ and the methodology for passivation. Mater. Res. 2016; 19, 51-6.

[39] NA Pike and OM Løvvik. Calculation of the anisotropic coefficients of thermal expansion: A firstprinciples approach. Comput. Mater. Sci. 2019; 167, 257-63.

[40] J Khosravi, MKB Givi, M Barmouz and A Rahi. Microstructural, mechanical, and thermophysical characterization of $\mathrm{Cu} / \mathrm{WC}$ composite layers fabricated via friction stir processing. Int. J. Adv. Manuf. Tech. 2014; 74, 1087-96.

[41] X Wang, C Hoffmann, C Hsueh, G Sarma, C Hubbard and J Keiser. Influence of residual stress on thermal expansion behavior. Appl. Phys. Lett. 1999; 75, 3294.

[42] T Sasaki, S Yoshida, T Ogawa, J Shitaka and C McGibboney. Effect of residual stress on thermal deformation behavior. Materials 2019; 12, 4141.

[43] N Li. 2016, Study the oxidation behavior and residual stresses of AISI 430 alloy in air with water vapor. Ph. D. Dissertation. University of Paris-Saclay, Gif-sur-Yvette, France.

[44] Z Wang, JL Grosseau-Poussard, B Panicaud, G Geandier, PO Renault, P Goudeau, N Boudet, N Blanc, F Rakotovao and Z Tao. Determination of residual stresses in an oxidized metallic alloy under thermal loadings. Metals 2018; 8, 913.

[45] J Godlewski and R Cadalbert. A new method for residual stress distribution analysis of corroded zircaloy-4 cladding. In: Proceedings of the International Symposium on Material Chemistry in Nuclear Environment, Japan. 1992, p. 3-12.

[46] SY Kwak and HY Hwang. Effect of heat treatment residual stress on stress behavior of constant stress beam. J. Comput. Des. Eng. 2018; 5, 137-43. 